\title{
Pyrolytic topping of coal-algae composite under mild inert conditions
}

\author{
Hope Baloyi ${ }^{1,2}{ }^{*}$, Gary Dugmore $^{2}$ \\ 1 Department of Chemistry, Faculty of Science, Nelson Mandela University, PO Box 77000, Port Elizabeth 6031, \\ South Africa \\ 2 InnoVenton: Institute for Chemical Technology and the Downstream Chemicals Technology Station, Nelson \\ Mandela University, PO Box 7700, Port Elizabeth 6031, South Africa \\ ORCID iDs: Baloyi: https://orcid.org/0000-0003-1499-2242 Dugmore: https://orcid.org/0000-0001-6597-9393
}

\begin{abstract}
Co-processing of coal and biomass has been a focus of several research studies aimed at addressing the negative environmental attributes associated with thermal processing of coal alone, as well as improving the thermal behaviour of coal. Biomass materials are regarded as a clean, renewable source, so thermal coprocessing of biomass with coal is considered an effective way to utilise coal in a sustainable manner. In this study, coal fines were blended with Scenedesmus microalgae slurry to form a coal-algae composite. Pyrolytic topping of coal-algae composite was performed at $450^{\circ} \mathrm{C}$ on a batch reactor. Parent fuels and resultant chars were analysed for their proximate properties using an Eltra thermostep TGA; a Vario EL cube Elementar was used to determine the elemental composition of the chars and oils. A simulated distillation (SimDis) method was used to determine the boiling point distribution of the produced oils. The objective of the study was to examine the effects of microalgae slurry on the pyrolytic behaviour of waste coal fines with respect to product yields, composition and quality. Results showed that the yields of volatile components from pyrolysis of coalalgae composite were high compared with those from pyrolysis of coal alone. A significant degree of deoxygenation, dehydrogenation and denitrification was observed in coal-algae char than coal char. SimDis results showed that the fossil bio-crude oil has different boiling point characteristics from coal tar. The study has shown that microalgae slurry has potential to influence the pyrolytic behaviour of waste coal under mild inert conditions.
\end{abstract}

Keywords: fossil bio-crude oil, resultant char, mild pyrolysis, coal-algae composite

\section{Highlights}

- Pyrolysis of the fuel composite results in low yields of char.

- Coal-algae composite pyrolysis results in a substantial degree of dehydrogenation.

- Fossil bio-crude oil contains more reactive compounds than coal tar.

- Coal-algae chars contains lower contents of sulphur and nitrogen than coal, which is desirable to reduce emissions of sulphur and nitrogen oxides during the combustion process

- Fossil bio-crude oil have compounds that are predominantly in the distillate fuel oil range

\section{Journal of Energy in Southern Africa 30(3):44-51 \\ DOI: https://dx.doi.org/10.17159/2413-3051/2019/v30i3a5763}

Published by the Energy Research Centre, University of Cape Town ISSN: 2413-3051

This work is licensed under a Creative Commons Attribution-ShareAlike 4.0 International Licence https://journals.assaf.org.za/jesa

Sponsored by the Department of Science and Technology

Corresponding author: +27 (0)41 504 2380;

email: baloyih82@gmail.com 


\section{Introduction}

Thermal co-processing of coal and biomass has received much research interest with an aim to explore ways to effectively use coal in a cleaner and sustainable manner as well as to improve the efficiency of coal conversion processes (Taba et al., 2012; Veras et al., 2009). Biomass is a clean, renewable energy source, with high thermal reactivity. In addition, biomass has a relatively high hydrogen content and high hydrogen-to-carbon $(\mathrm{H} / \mathrm{C})$ ratio compared to coal, which is important in improving the yields of coal pyrolysis products during co-pyrolysis of coal and biomass (Chen et al., 2012; Zhang et al., 2007). The use of biomass can potentially influence the thermal behaviour of coal under pyrolysis conditions through the interaction of the biomass volatiles with coal at low temperature range $\left(200-400{ }^{\circ} \mathrm{C}\right)$ (Baloyi and Dugmore, 2018; Wu et al., 2014; Idris et al., 2010). However, in fixed bed co-pyrolysis the interaction of biomass volatiles and coal particles occurs at temperatures ranging from $500-700{ }^{\circ} \mathrm{C}$ (Park et al., 2010).

Research work on the thermal co-processing of coal with biomass has shown that, despite the two fuels having different chemical characteristics, the co-processing of the two fuels is possible (Idris et al., 2010; Kumabe et al., 2007; Vuthaluru et al., 2004). Studies have shown that biomass (agricultural, woody or algal) is thermally reactive, and have observed that, when co-pyrolysed with coal, the addition of a varying fraction of biomass in the blends increases the reactivity of coal, due to an increase in the volatiles (Baloyi and Dugmore, 2018; Ferrara et al., 2014; Kirtania and Bhattacharya, 2013; Chen et al., 2012; Idris et al., 2010). Several other researchers investigated the possible synergistic effects on product distribution during co-pyrolysis of biomass and coal. Li et al. (2013) studied the co-pyrolysis behaviour of woody biomass and coal in a drop tube reactor and fixed bed reactor and observed that the interaction between the two fuels happens in the gaseous phase at higher temperatures - above $1000^{\circ} \mathrm{C}$. Soncini et al. (2013), observed co-pyrolysis synergies on product yields (tar, volatiles and gases), particularly for co-pyrolysis of biomass and low ranked coal at temperatures above $900{ }^{\circ} \mathrm{C}$ in a semidrop tube reactor. Wei et al. (2011) observed that the existence of co-pyrolysis synergies results in the production of more liquid products.

Pyrolysis is a thermochemical conversion process that precedes combustion and gasification processes. However, as an independent process, it can be used to transform solid fuels to yield liquid tar and gaseous products as well as devolatilised resultant char in an oxygen-free environment. Coal pyrolysis involves the formation of reactive radicals (i.e. $\cdot \mathrm{CH}_{2}$ and $\bullet \mathrm{O}-)$ that undergoes numerous secondary chemical reactions such as cracking, re-polymerisation, and carbonisation. These formed radicals are stabilised by the addition of hydrogen to form condensable and non-condensable volatile products (Seo et al., 2011; Demirbas, 2003). Under co-pyrolysis conditions, the radical structures generated by coal pyrolysis are stabilised by the hydrogen donated by the biomass to promote the generation of liquid products as well as to improve gas yields and produce other chemicals (Soncini et al., 2013; Li et al., 2011).

This study focuses on the mild pyrolysis of a coalalgae composite formed by blending photosynthetically active Scenedesmus microalgae slurry with a low-ranked fine, discard coal. Coal-algae composite pyrolysis aims at improving the product yields, composition and quality of derived products as compared to the pyrolysis of untreated discard coal. It further aims at yielding a fuel oil that possesses a combination of biofuel and fossil fuel characteristics, as well as a semi-devolatilised coal in a single production step. Scenedesmus microalgae biomass is a high hydrogen-containing fuel with attractive chemical properties and can be considered environmentally friendly, having a low ash yield $(<8.0$ wt. \%) and low sulphur content $(<0.5$ wt. \%) as shown in Table 1.

\section{Table 1: Chemical properties of Scenedesmus microalgae biomass.}

\begin{tabular}{ccc|ccccc}
\hline \multicolumn{2}{c|}{$\begin{array}{c}\text { Proximate (wt. \%, } \\
\text { dry basis) }\end{array}$} & \multicolumn{5}{|c}{ Ultimate (wt. \%, dry ash free } \\
basis)
\end{tabular}

Formation of coal-algae composite can be viewed as a method to improve the thermal processing of discard coal. Low-ranked coals are believed to have the ability to easily interact with a biomass source during pyrolysis process, thereby bringing in synergies, and can capture the donatable hydrogen from a biomass source (Quan and Gao, 2016). In this study, photosynthetically active Scenedesmus microalgae slurry is brought into contact with fine discard coal $(<150 \mu \mathrm{m})$ by mixing and continuous stirring overnight. This allows the microalgae slurry (at $10 \%$ loading) to blend or mix with the coal fines and form the fuel composite (coal-algae composite), which is attained after decantation of the water phase following centrifugation of the wet coal-microalgae mixture. The wet solid mixture (coal-algae composite) is subjected to overnight drying at $40^{\circ} \mathrm{C}$.

This paper reports on the yields, composition and properties of the derived products from pyro- 
lytic topping of coal and coal-algae composite conducted on an in-house-designed batch reactor, at atmospheric pressure under mild inert conditions. Parent fuels and resultant chars were analysed for their proximate and ultimate properties. Simulated distillation (SimDis) by gas chromatography analysis was performed to determine the boiling point characteristics and estimation of petroleum fractions of the produced oils. The heating properties and elemental composition of the produced oils was done by estimation of the higher heating values (HHV) and elemental (CHNS) analysis respectively.

\section{Experimental}

\subsection{Pyrolysis experiments}

Pyrolytic topping experiments were carried out on a batch reactor as shown in Figure 1. A desired amount of sample was loaded into a horizontal tube reactor $(700 \mathrm{~mm} \times 65 \mathrm{~mm}$ ) that had a carrying capacity of $600 \mathrm{~g}$ of sample. To start the experiment, the packed tube reactor was slid through the furnace, the chiller unit (set at $2{ }^{\circ} \mathrm{C}$ ) was switched on to allow the inflow and outflow of circulation of chilled water in the condenser unit. The sample was purged with nitrogen at $4 \mathrm{~L} / \mathrm{min}$ to displace any residual air. After purging, the thermo-control unit was switched on and the four heating elements were set at $450{ }^{\circ} \mathrm{C}$. During the experiment, the nitrogen flow was kept at $0.4 \mathrm{~L} / \mathrm{min}$. The temperature within the reactor tube was monitored using an inserted K-type thermocouple. At the end of the experiment, the twophased liquid product (pyrolytic water and oil phase) were drained out into a pre-weighed sample bottle. The devolatilised coal was collected from the reactor tube. The two-phase liquid was separated by storing it in a laboratory refrigerator at $4{ }^{\circ} \mathrm{C}$; the waxlike tar product settled at the bottom and the pyrolytic water phase could be decanted to a clean preweighed bottle. The tarry phase derived from coalalgae composite pyrolysis was described as fossilbio-crude oil. The product (reaction water, oils, chars) yields were determined as the ratio mass of product measured to the initial mass of the sample fed, expressed as weight percentage. The mass of sample fed was corrected to an ash-free basis, based on Equation 1.

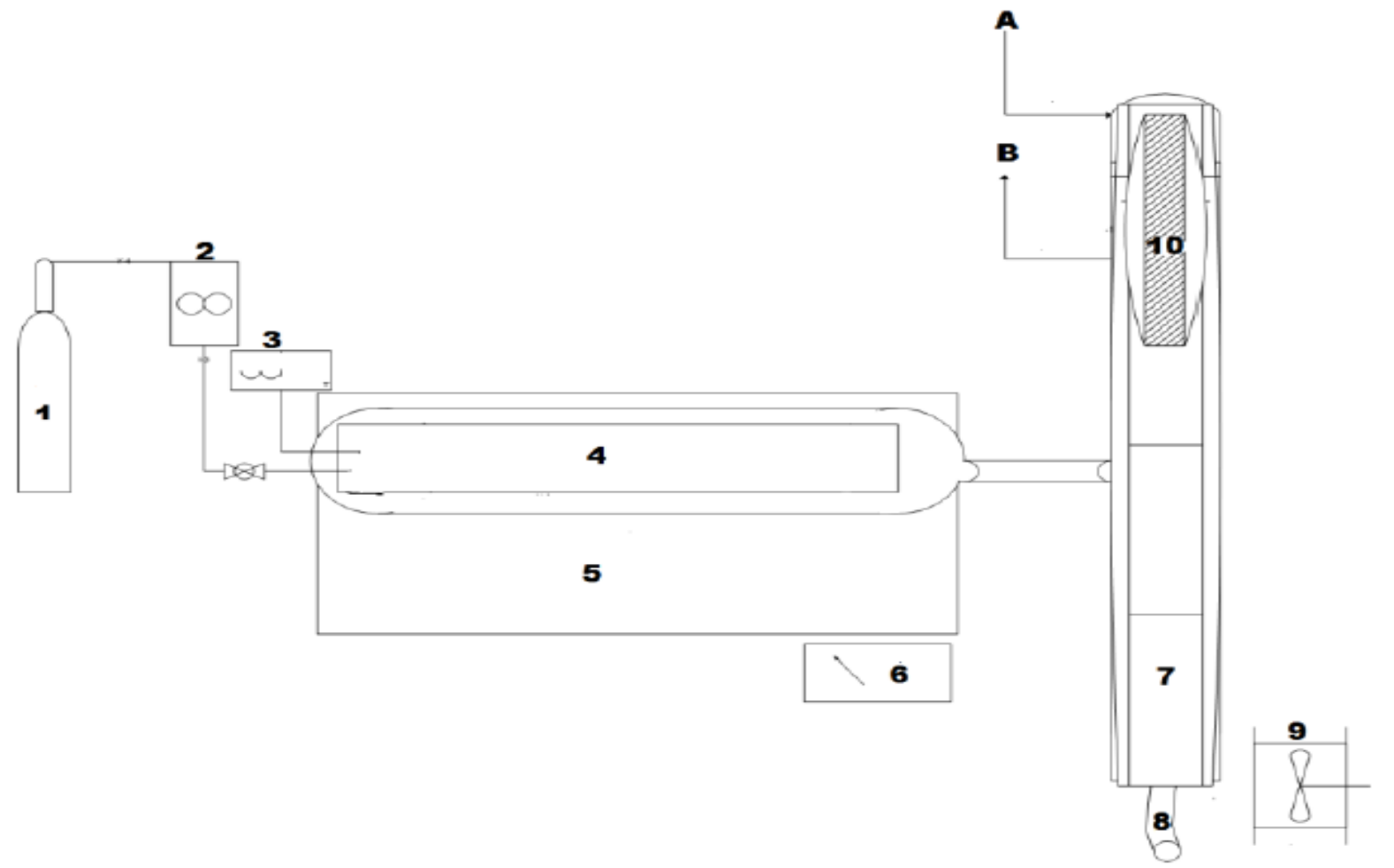

(1- nitrogen gas; 2 - flow meter; 3 - digital thermometer-coupled to thermocouple; 4 - reactor tube; 5 - furnace; 6 thermo-control unit (with four heating elements); 7 - receiver; 8 - drain valve; 9 - heater; 10 - condenser a outflow water-chiller, $b$ - inflow water-chiller).

Figure 1: Schematic representation of the pyrolysis experimental set-up. 


$$
M s_{\text {ashfree }}=M s_{f e d}-\left[\left(\frac{\text { Ash yield }}{100}\right) \times M s_{f e d}\right]
$$

The total product (reaction water, oil, char) yields (wt \%) were calculated on ash free basis based on Equation 2.

$$
\text { Product yield }=\frac{M p}{M s_{\text {ashfree }}} \times 100
$$

where $\mathrm{Ms}_{\mathrm{fed}}=$ mass of sample fed $(\mathrm{g}) ; \mathrm{Mp}=$ mass of pyrolysis product $(\mathrm{g})$; $\mathrm{Ms}_{\text {ashfree }}=$ sample fed $(\mathrm{g})$ on ash free basis.

The ash yield (wt \%) was obtained from the proximate analysis of the sample. Gas yields were calculated by difference.

\subsection{Compositional analysis}

2.2.1 Proximate, ultimate and calorific value analysis Standard methods (ASTM D-7582) were used to determine the proximate properties (moisture, volatile matter, ash yield and fixed carbon (by difference) of the solid fuels. Proximate analyses were performed on an Eltra Thermostep Thermogravimetric analyser (TGA). A Vario EL cube Elementar (ASTM D-3176) was used for determining the elemental $\mathrm{C}, \mathrm{H}, \mathrm{N}, \mathrm{S}$ and $\mathrm{O}$ (by difference) of the solid fuels and derived oils. Higher heating values (HHV) of the derived oils were estimated as a function of carbon (C), hydrogen $(\mathrm{H})$, sulphur $(\mathrm{S})$ and oxygen $(\mathrm{O})$, according to the Dulong's formula as shown in Equation 3 (Channiwala and Parikh, 2002).

$$
\begin{aligned}
& \operatorname{HHV}(\mathrm{MJ} / \mathrm{kg})= \\
& (0.3383 \times \mathrm{C})+1.443[H(0 / 8)]+(0.0942 \times S)(3)
\end{aligned}
$$

\subsubsection{Simulated distillation by gas chromatography}

The SimDis analyses of the derived oils were performed on an Agilent Technologies 7890A GC in accordance with standard method D2887 for the determination of the boiling range distribution and the estimation of petroleum fractions in the fossil biocrude oil. A calibration blend was prepared from 2 $\mathrm{ml}$ of Polywax (C5-C44) (AC no: 25950.150) and $15 \mathrm{~g}$ of carbon disulphide $\left(\mathrm{CS}_{2}\right)$ in a $20 \mathrm{ml}$ volumetric flask to establish the correlation between retention time and distillation temperature. A reference oil sample (AC no: 25650.150) was used for validation of the system. $\mathrm{CS}_{2}$ was run as blank prior to calibration and analysis of samples to verify the system for cleanliness and column performance. About $2 \mathrm{~g}$ of the oil was dissolved in $10 \mathrm{ml}$ of dichloromethane (DCM) to form a DCM solution. $1.5 \mathrm{ml}$ of the DCM solution was transferred into a clean vial, and $0.1 \mu \mathrm{L}$ of the solution was injected into the column for analysis. Gas chromatography (GC) operating conditions for the SimDis analysis of the produced oils are summarised in Table 2.
Table 2: Gas chromatography operating conditions for the SimDis analyses.

Flame ionisation detector

Temperature: $200{ }^{\circ} \mathrm{C} ; \mathrm{H}_{2} 40 \mathrm{ml} / \mathrm{min}$; Air $295 \mathrm{ml} / \mathrm{min}$

Oven programme

Temperature: $100{ }^{\circ} \mathrm{C}$; Time: 0.5-1.2 min; Rate: $15^{\circ} \mathrm{C} / \mathrm{min}$

Injector programme

Temperature: $350{ }^{\circ} \mathrm{C}$; Time: 0-2.5 min: Rate: $35^{\circ} \mathrm{C} / \mathrm{min}$

\section{Column}

Injector volume: $0.1 \mu \mathrm{l}$; Column flow: $19 \mathrm{ml} / \mathrm{min}$; gas flow (Helium): $26 \mathrm{ml} / \mathrm{min}$; column dimension: $10 \mathrm{~m}$ X $0.53 \mathrm{~mm}$

\section{Results and discussion}

Yields of pyrolysis products derived at $450{ }^{\circ} \mathrm{C}$ are presented in Figure 2, which makes it evident that pyrolysis of the fuel composite results in low yields of char and high yields of volatile components than pyrolysis of coal alone. The results show that the presence of microalgae biomass in the fuel composite has an influence on the devolatilisation of coal under mild pyrolysis conditions. As shown in Table 3 , the coal-algae composite contains high volatile matter content and low fixed carbon than raw coal.

It can further be observed that the resultant coalalgae char contains high amount volatile matter than coal char; however, the pyrolysis of the coal-algae composite results in the retention of a lesser amount of volatile matter content $(<50 \%)$ as compared to coal pyrolysis. Moreover, the substantial devolatilisation during coal-algae pyrolysis results in approximately $80 \%$ of the fixed carbon in the resultant coal-algae char, which is relatively lower than the $90 \%$ of fixed carbon retained in the coal char. The extent to which the volatiles and fixed carbon content were retained in the resultant chars following mild pyrolysis is indicated by the retention efficiency (RE), which was calculated according to Equation 4.

$$
R E=\frac{\text { Mass of residual char }}{\text { Mass of parent sample }} \times \frac{\text { Xchar }}{\text { Xsample }}
$$

where X denotes proximate property (volatile matter or fixed carbon) of the fuel (parent sample or resultant char) as measured on an Eltra Thermostep TGA.

Table 4 shows that pyrolysis of parent fuels results in a decreasing trend in the hydrogen and oxygen contents of resultant chars, which is attributable to the transitional changes that occur during pyrolysis. Reductions in oxygen and hydrogen contents are a result of an increase in the release of volatile components. A decrease in the hydrogen content in 
(c)
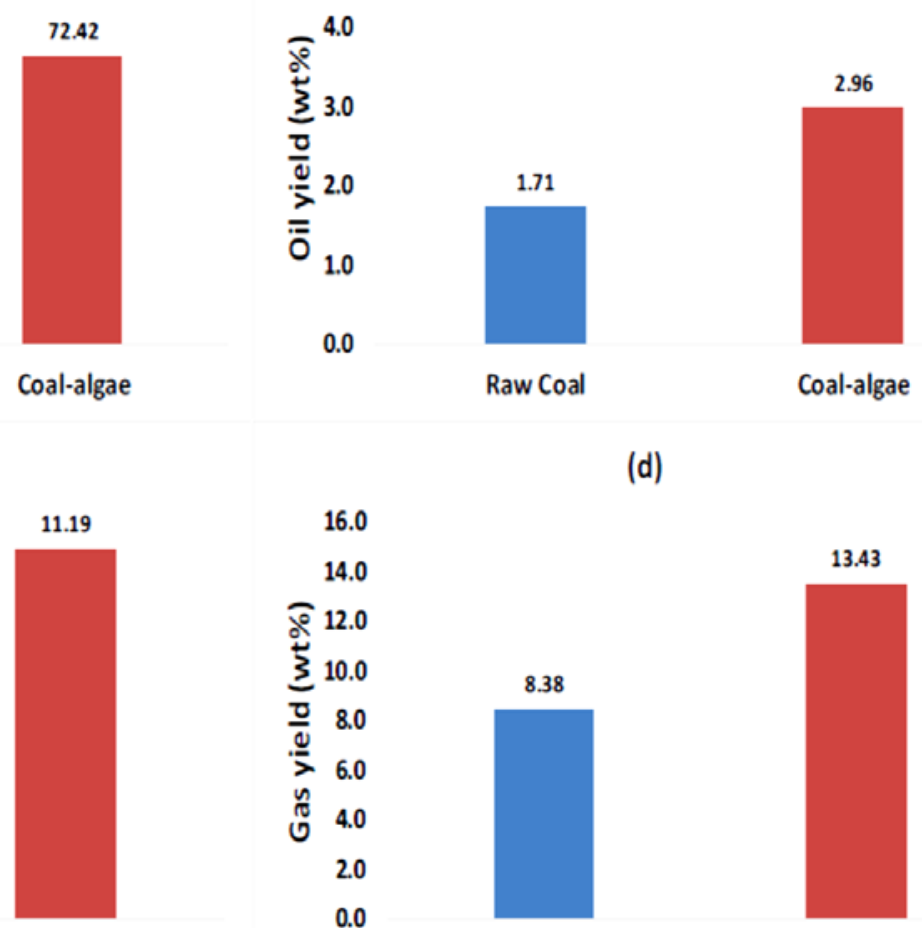

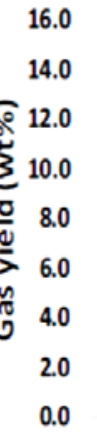

Coal-algae

Coal-algae

(d)
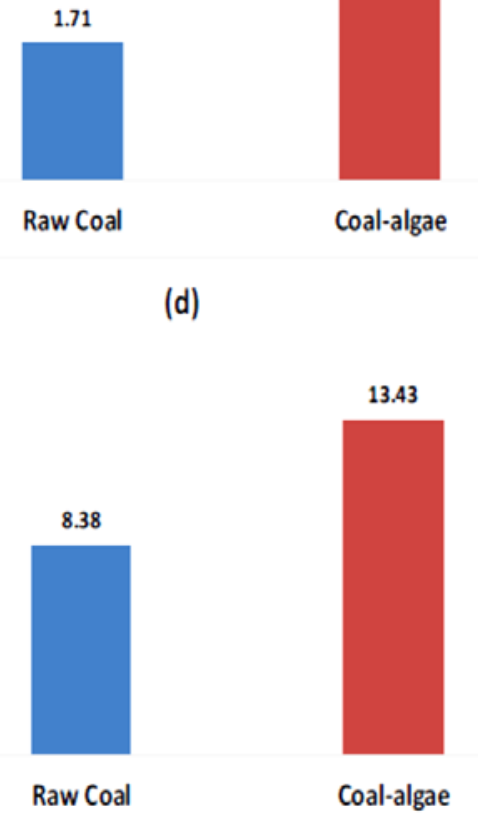

Figure 2: Product yields: (a) resultant chars; (b) coal tar and fossil bio-crude oil; (c) pyrolytic water; (d) product gas.

Table 3: Chemical properties of coal, coal-algae and resultant chars.

\begin{tabular}{lcccc}
\hline \multicolumn{1}{c}{ (Weight \%, dry basis) } & Raw coal & Coal char & Coal-algae & $\begin{array}{c}\text { Coal-algae } \\
\text { char }\end{array}$ \\
\hline Volatile matter & 25.4 & 15.1 & 30.1 & 19.2 \\
Ash yield & 20.8 & 27.3 & 19.6 & 23.3 \\
Fixed carbon & 53.8 & 57.7 & 50.3 & 57.6 \\
Retention efficiency (volatile) & & 0.50 & & 0.46 \\
Retention efficiency (fixed carbon) & & 0.90 & & 0.82 \\
\hline
\end{tabular}

Table 4: Ultimate analysis of coal, coal-algae and resultant chars (dry, ash free basis).

\begin{tabular}{lccccc}
\hline & $w t . \%$ C & $w t . \% H$ & $w t . \%$ N & wt. \% S & wt. \% O \\
\hline Raw coal & 79.3 & 4.0 & 2.2 & 1.0 & 13.4 \\
Coal char & 81.8 & 3.5 & 2.9 & 0.8 & 11.0 \\
Coal-algae & 73.6 & 4.5 & 3.0 & 0.6 & 18.4 \\
Coal-algae char & 79.5 & 3.0 & 2.2 & 0.5 & 14.8 \\
\hline
\end{tabular}

wt. = weight: $C, H, N, S, O=$ carbon, hydrogen, nitrogen, sulphur, oxygen respectively

the chars is due to hydrogen transferred from hydroaromatic groups within the parent fuels to stabilise the forming radical groups, to promote the formation of gaseous hydrocarbon and liquid products (Soncini et al., 2013). Oxygen reduction is generally because of the elimination of oxygen in the parental fuels in various forms, such as water and oxides of carbon during pyrolysis (Serio et al., 1987; Yu et al., 2007). It can be noted that coal-algae composite pyrolysis results in a greater degree of dehydrogenation, deoxygenation and denitrification than coal pyrolysis, as reflected in the contents of elemental 
hydrogen, oxygen and nitrogen of the resultant chars. It can be further noted that coal-algae chars contain lower contents of sulphur and nitrogen than coal, which is desirable to reduce emissions of sulphur and nitrogen oxides during the combustion process should these chars be used as input feedstock for such processes (Pedersen et al., 1996).

The elemental composition and estimated higher heating values of fossil bio-crude oil and of coal tar obtained from the pyrolytic topping of raw coal and coal-algae composite under mild conditions is presented in Table 5. As shown there, the pyrolysis of coal-algae composite produces fossil bio-crude oil with relatively higher amounts of oxygen and hydrogen and lower carbon content than coal tar. The high oxygen content in the fossil bio-crude oil suggests that the fossil bio-crude oil contains more reactive compounds than coal tar (Vreugdenhil and Zwart, 2009). However, the high oxygen content results in the lower HHV, and hence the lowering of the oxygen content of the fossil bio-crude oil would be required to improve the heating value (Patel and Hellgardt, 2015).

Boiling point characteristics of the produced oils are shown in Table 6. The Kegler method (Escallon, 2008) was used to calculate the average boiling point (on mass percentage recovered) of the fossil bio-crude oil and coal tar from selected temperature cut-point. It can be observed that the pyrolysis of coal-algae composite produced an oil product with a slightly higher average boiling point than coal tar. Boiling points of the fossil bio-crude oil at various cut-points are much higher than those of coal tar, except at $90 \%$ recovered mass, where the boiling point is the same as that of the coal tar.

The boiling point fractions of the produced oils are shown in Figure 3, which shows that the produced fossil bio-crude oil has compounds that are predominantly in the distillate fuel oil range (277$343{ }^{\circ} \mathrm{C}$ ) and are in higher proportions (25.5 wt. \% distillate fuel oil) than (17.2 wt. \%) coal tar. Moreover, fossil bio-crude oil contains relatively high amounts of compounds compared to coal tar in the higher boiling point cut $\left(455-566^{\circ} \mathrm{C}\right)$. Generally, there are smaller quantities of compounds in fossil bio-crude oil (6.9 wt. \%) and coal tar (7.4 wt. \%) that are confined in the low boiling point heavy naphtha region $\left(121-191^{\circ} \mathrm{C}\right)$, and a large quantity of compounds are found in the light vacuum gas oil fraction. However, the compounds in the fossil biocrude oil within this region are relatively lower than those in the coal tar.

Table 5: CHNS-O distribution and higher heating values (HHV) of fossil bio-crude oil and coal tar.

\begin{tabular}{lcccccc}
\hline & $w t . \% C$ & $w t . \% H$ & $w t . \% N$ & $w t . \% S$ & $w t . \% O$ & $H H V(M J / k g)$ \\
\hline Coal tar & 74.1 & 10.3 & 1.9 & 0.4 & 13.3 & 37.6 \\
Fossil bio-crude oil & 59.7 & 12.4 & 2.8 & 0.3 & 24.8 & 33.7
\end{tabular}

wt. = weight: $C, H, N, S, O=$ carbon, hydrogen, nitrogen, sulphur, oxygen respectively

Table 6: Average boiling points $\left({ }^{\circ} \mathrm{C}\right)$ of the produced fossil bio-crude oil and coal tar.

\begin{tabular}{lccc}
\hline & Mass recovered & Coal tar & Fossil bio-crude oil \\
\hline Cut-point & weight $\%$ & \multicolumn{2}{c}{ Boiling point $\left({ }^{\circ} \mathrm{C}\right)$} \\
\hline T10 & 10 & 200.2 & 204.4 \\
T30 & 30 & 269.6 & 277.0 \\
T50 & 50 & 328.6 & 333.4 \\
T70 & 70 & 387.4 & 390.0 \\
T90 & 90 & 466.2 & 466.8 \\
& AveBP & 330.4 & 334.3 \\
\hline
\end{tabular}




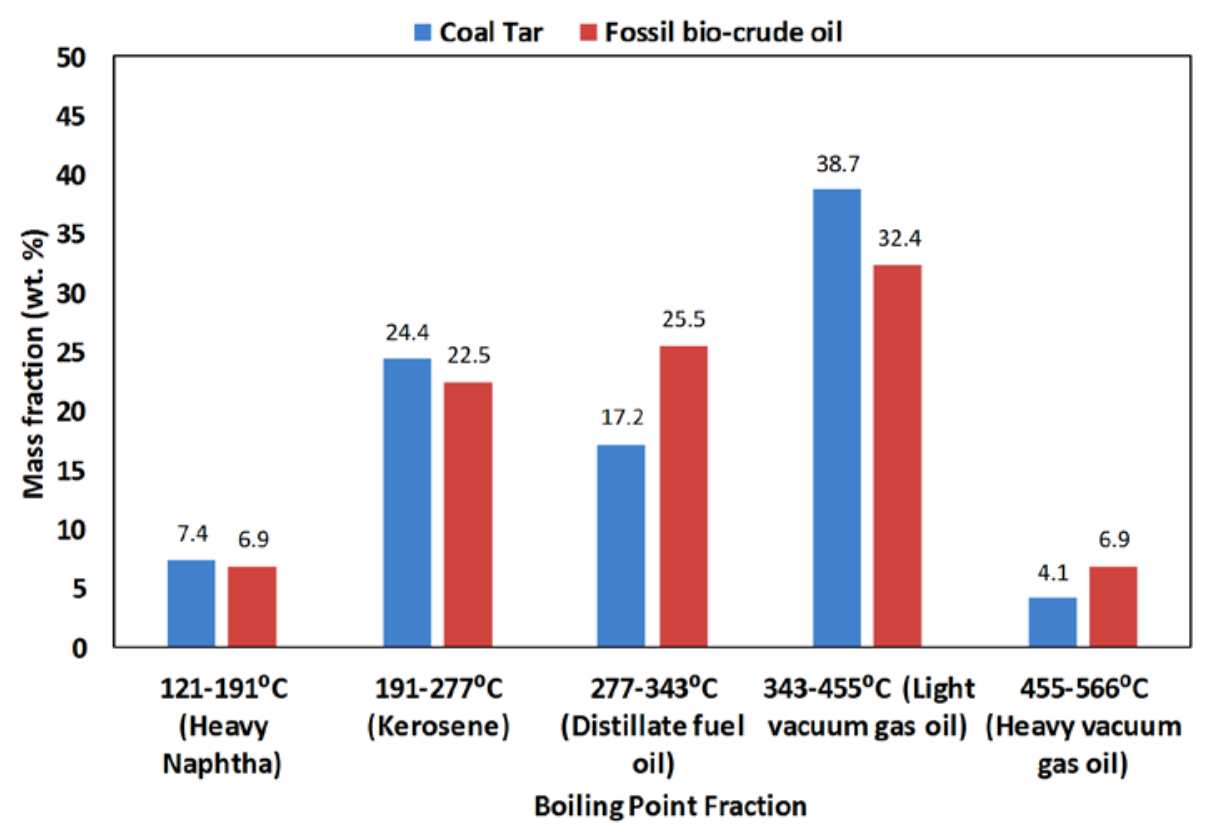

Figure 3: Simulated distillation of coal tar and fossil bio-crude oil.

\section{Conclusions}

Pyrolytic topping of coal-algae composite has shown that it is possible to pyrolyse coal-algae composite under mild reaction conditions and yield a char with a substantial degree of deoxygenation, dehydrogenation and denitrification compared to the resultant coal char. Furthermore, coal-algae composite results in significant levels of devolatilisation, as reflected in the high amounts of volatile components produced during coal-algae pyrolysis. Fossil biocrude oil has properties that potentially differ from those of coal-derived tar, with notable differences in the chemical composition as well as the distribution of boiling point fractions. Mild pyrolysis of coal-algae composite may be a suitable process to produce a clean coal residue product that can be used as input fuel for cleaner combustion processes.

\section{Acknowledgements}

The information presented in this paper is based on a doctoral research financially supported by National Research Foundation (PDP Doctoral Fellowship Grant UID: 79000) and formed part of the Microalgae-to-Energy (MA2E) Project at InnoVenton: Institute for Chemical Technology supported through the Department of Science and Technology initiative. Opinions expressed, and conclusions arrived at are those of the author(s) and are not necessarily to be attributed to the National Research Foundation or the Department of Science and Technology.

\section{Author roles}

Hope Baloyi: Write-up of the article, data collection and all the analytical discussions here.

Gary Dugmore: Project supervision, research formulation and technical advice

\section{References}

Baloyi, H and Dugmore, G. 2018. Influences of microalgae biomass on the thermal behaviour of waste coal fines. Journal of Energy in Southern Africa 30(1): 1-7. http://dx.doi.org/10.17159/2413-3051/2018/v30i1a5763.

Channiwala, S.A and Parikh, P.P. 2002. A unified correlation for the estimation HHV of solid, liquid and gaseous fuels. Fuel 81(8): 1051-1063. https://doi.org/10.1016/S0016-2361(01)00131-4.

Chen, C., Ma, A and He, Y. 2012. Co-pyrolysis characteristics of microalgae Chlorella vulgaris and coal through TGA. Bioresource Technology 117: 264-273. https://doi.org/10.1016/j.biortech.2012.04.077.

Demirbas, A. 2003. Sustainable cofiring of biomass with coal. Energy Conversion \& Management 44(9): 1465-1479. https://doi.org/10.1016/S0196-8904(02)00144-9.

Escallon, M.M. 2008. Petroleum and petroleum/coal blends as feedstocks in laboratory scale and pilot scale cokers to obtain carbons of potentially high value. $\mathrm{PhD}$ thesis, Pennsylvania State University, USA.

Ferrara, F., Orsini, A., Plaisant, A and Pettinau, A. 2014. Pyrolysis of coal, biomass and their blends: Performance assessment by thermogravimetric analysis. Bioresource Technology 171: 433-441.

https://doi.org/10.1016/j.biortech.2014.08.104. 
Idris, S.S., Rahman, N.A., Ismail, K., Alias, A.B., Rashid, Z.A and Aris, M.J. 2010. Investigation on thermochemical behaviour of low rank Malaysian coal, tar palm biomass and their blends during pyrolysis via thermo gravimetric analysis. Bioresource Technology 101(12): 4584-4592. https://doi.org/10.1016/j.biortech.2010.01.059.

Kirtania, K and Bhattacharya, S. 2013. Pyrolysis kinetics and reactivity of algae-coal blends. Biomass and Bioenergy 55: 291-298. https://doi.org/10.1016/j.biombioe.2013.02.019.

Kumabe, K., Hanaoka, T., Fujimoto, S., Minowa, T and Sakanishi, K. 2007. Co-gasification of woody biomass and coal with air and steam. Fuel 86(5-6): 684-689. https://doi.org/10.1016/j.fuel.2006.08.026.

Li, S., Chen, X., Wang, L., Liu, A and Yu, G. 2013. Co-pyrolysis behaviors of saw dust and Shenfu coal in drop tube furnace and fixed bed reactor. Bioresource Technology 148: 24-29. http://dx.doi.org/10.1016/j.biortech.2013.08.126.

Park, D.K., Kim, S.D., Lee, S.H and Lee, J.G. 2010. Co-pyrolysis characteristics of sawdust and coal blend in TGA and a fixed bed reactor. Bioresource Technology 101(15): 6151-6156. https://doi.org/10.1016/i.biortech.2010.02.087.

Patel, B and Hellgardt, K. 2015. Hydrothermal upgrading of algae paste in a continuous flow reactor. Bioresource Technology 191: 460-468. http://dx.doi.org/10.1016/j.biortech.2015.04.012.

Pedersen, L.S., Nielsen, H.P., Kiil S., Hansen, L.A., Dam-Johansen, K., Kildsig F., Christensen, J., Jespersen, P. 1996. Full-scale co-firing of straw and coal. Fuel 75 (13): 1584-1590.

Quan, C and Gao, N. 2016. Copyrolysis of biomass and coal: A review of effects of parameters, product properties, and synergistic mechanisms. BioMed Research International. Article ID 6197867, 1-11.

Seo, G.K, Park, S.S, Kim, T.Y., Hwang, J and Yu, T. 2011. Study of coal pyrolysis by thermo-gravimetric analysis (TGA) and concentration measurements of the evolved species. Journal of Analytical and Applied Pyrolysis 92(1): 209-216. https://doi.org/10.1016/j.jaap.2011.05.012.

Serio, M.A, Hamblen, D.G., Markham, J.R and Solomon, P.R. 1987. Kinetics of volatile product evolution in coal pyrolysis: Experiment and theory. Energy \& Fuels 1(2): 138-152. https://doi.org/10.1021/ef00002a002.

Soncini, R. M., Means, N.C and Weiland, N.T. 2013. Co-pyrolysis of low rank coals and biomass: Product distributions. Fuel 112: 74-82. https://doi.org/10.1016/j.fuel.2013.04.073.

Taba, L.E., Irfan, M.F., Daud, W.A.M.W and Chakrabarti, M. H. 2012. The effect of temperature on various parameters in coal, biomass and co-gasification: A review. Renewable and Sustainable Energy16(8): 5584-5596. http://dx.doi.org/10.1016/j.rser.2012.06.015.

Veras, C. A. G., Carvalho, J.A and Ferreira, M.A. 2002. The chemical percolation devolatilization model applied to the devolatilization of coal in high intensity acoustic fields. Journal of the Brazilian Chemical Society 13(3): 358-367. http://dx.doi.org/10.1590/S0103-50532002000300001.

Vreugdenhil, B.J and Zwart, R.W.R. 2009. Tar formation in pyrolysis and gasification. Energy Research Centre of the Netherlands. ECN-E--08-087, Petten.

Vuthaluru, H.B. 2004. Thermal behaviour of coal/biomass blends during co-pyrolysis. Fuel Processing Technology 85(2-3): 141-155. https://doi.org/10.1016/S0378-3820(03)00112.

Wei, L., Zhang, L and Xu, S. 2011. Effects of feedstock on co-pyrolysis of biomass and coal in a free-fall reactor. Journal of Fuel Chemistry and Technology 39(10): 728-734. https://doi.org/10.1016/S1872-5813(11)60044-3.

Wu, Z., Wang, S., Zhao, J., Chen, L., Meng, H. 2014. Synergistic effect on thermal behavior during co-pyrolysis of lignocellulosic biomass model components blend with bituminous coal. Bioresource Technology 169: 220-228. https://doi.org/10.1016/j.biortech.2014.06.105.

Yu, J., Lucas, J.A and Wall, T.F. 2007. Formation of the structure of chars during devolatilization of pulverized coal and its thermo properties: A review. Progress in Energy and Combustion Science 33(2): 135-170. http://dx.doi.org/10.1016/j.pecs.2006.07.003. 